\title{
Tortum Gölü Yüzey Sedimentlerindeki Metal Birikiminin Ekolojik İndeksler Yolu ile Kapsamlı Risk Değerlendirmesi
}

\section{Serkan Kükrer* \\ Ardahan Üniversitesi, Insani Bilimler ve Edebiyat Fakültesi, Coğrafya Bölümü, 75000 Ardahan, Türkiye}

\section{A K A L E B İ L G İ S İ}

Geliş 31 Ağustos 2016

Kabul 18 Ekim 2016

Çevrimiçi bask1, ISSN: 2148-127X

Anahtar Kelimeler:

Ekolojik risk değerlendirmesi

Sediment

Ağır metal

Ekolojik indeks

Tortum Gölü

*Sorumlu Yazar:

E-mail: kukrerserkan@gmail.com

\section{Ö Z E T}

Bu çalışmada Tortum Gölü yüzey sedimentindeki bazı ağır metallerin birikiminden kaynaklanan ekolojik riskler zenginleşme faktörü $(\mathrm{EF})$, kontaminasyon faktörü $(\mathrm{CF})$, kirlilik yük indeksi (PLI), potansiyel ekolojik risk indeksi (PER) ve ortalama muhtemel etki konsantrasyonu oranı (mPEC-Q) indeksi kullanılarak değerlendirilmiştir. Sediment örnekleri altı istasyondan Van Veen Grap kullanılarak toplanmış ve sedimentin ağır metal ve organik karbon içeriği belirlenmiştir. Sonuçlara göre sedimentte düşük-orta düzeyli kontaminasyon belirlenmiştir. En yüksek EF değeri bölgede kullanılan fosil yakıt kullanımından kaynaklı olduğu düşünülen Cd 'ye aittir. PLI ve PER değerleri gölde ağır metallere bağlı düşük ekolojik risk işaret ederken, mPEC-Q değerleri Gölü \%15-29 risk ile düşük-orta öncelikli alan olarak değerlendirmektedir.

Turkish Journal Of Agriculture - Food Science And Technology, 4(12): 1185-1191, 2016

\section{Comprehensive Risk Assessment of Heavy Metal Accumulation in Surface Sediment of Lake Tortum Based on Ecological Indices}

\section{A R T I C L E I N F O}

Article history:

Received 31 August 2016

Accepted 18 October 2016

Available online, ISSN: $2148-127 \mathrm{X}$

Keywords:

Ecological risk assessment

Sediment

Heavy metal

Ecological index

Lake Tortum

\section{*Corresponding Author:}

E-mail: kukrerserkan@gmail.com

\section{A B S T R A C T}

In this study, ecological risks arising from the accumulation of some heavy metals in surface sediments of Lake Tortum are discussed based on the use of ecological indices, such as enrichment factor (EF), contamination factor (CF), pollution load index (PLI), potential ecological risk index (PER) and the mean probable effect concentration quotient (mPEC-Q). Sediment samples were collected from six different sites using Van Veen grab and heavy metal and organic carbon content of sediments were determined. Results testify to the existence of minimal to moderate contamination in lake sediment. The highest value for the enrichment factor pertains to $\mathrm{Cd}$ caused by the use of fossil fuels in settlement areas in the lake catchment. PLI and PER estimations, on the other hand, reveals the presence of low heavy metals-induced ecological risk in lake sediments. Ranging between $15 \%$ and $29 \%$, mPEC-Q values are indicative of the fact that Lake Tortum is a low-moderate priority site in terms of toxicity level caused by heavy metals.

\section{Giriş}

Göller tatlı su kaynağı olmaları, yeraltı sularını takviye etmeleri, iklim üzerine olumlu etki yapmaları ve çevresel şartları düzenlemeleri gibi özellikleri sebebiyle önemli ekosistemlerdir (Hou ve ark., 2013). Göller kesintisiz alıcı özelliğine sahip olduklarından kirlilikten birincil düzeyde etkilenmektedirler (Mutlu ve ark., 2014). Ülkemiz gibi gelişmekte olan ülkelerde yüzeysel su kaynakları kullanım, sulama ve içme suyu olarak değerlendirilmesine rağmen aynı zamanda deşarj alanı olarak da kullanıldığından (Mutlu ve Tepe, 2014), teknik ve demografik ilerlemelere paralel olarak gelişen bu durumdan diğer ekosistemler gibi göl ekosistemleri de olumsuz etkilenmekte ve maalesef günden güne artan şekilde birçok kirleticinin deşarj ve birikim alanı haline gelmektedirler. Hızlı şehirleşme, sanayileşme, tarımsal uygulamalar ve kömür yakılması toprakta, suda, -özellikle halkın kullanımında olan su kaynaklarında- sokak tozlarında, sedimentte, insan tarafindan tüketilen sucul canlılarda ve besin zincirinde görülen ağır metal birikiminin başta gelen sorumlusu olarak görülmektedir (Yang ve ark., 2014; Tao ve ark., 2012 ;Cheng ve ark., 2015; Yi ve ark., 2011). As, $\mathrm{Cd}, \mathrm{Hg}, \mathrm{Pb}, \mathrm{Cu}, \mathrm{Cr}, \mathrm{Mn}, \mathrm{Zn}$ gibi elementler şehir ve sanayi atıkları ile alıcı ortama taşınmaktadır (Nriago ve Pacyna, 1988). Bu bileşikler 
organizmaları ya vücutlarında birikerek doğrudan ya da besin zinciri içinde üst seviyelere transfer yoluyla dolaylı olarak etkileyebilirler (Altındağ ve Yiğit, 2005).

Ağır metal birikimlerinin nasıl değerlendirileceği ve insan katkısının doğal konsantrasyonlardan nasıl ayırt edileceği önemli bir sorundur (Bing ve ark., 2013). Ağır metallerin birikimini ve yarattıkları çevre sorunlarını değerlendirebilmek için birçok indeks geliştirilmiştir. Örneğin antropojenik kaynaklı birikimleri belirleyebilmek için zenginleşme faktörü, kontaminasyon faktörü, jeoakümülasyon indeksi gibi metallerin güncel ve ardalan (doğal jeolojik yapıdan gelen metal konsantrasyonları) içeriklerini kullanan indeksler, olası ekolojik riskleri tespit edebilmek için kirlilik yük indeksi, potansiyel ekolojik risk indeksi ve ortalama olası etki konsantrasyonu oranı (mPEC-Q) sıkça kullanılan indekslerdir (Yang ve ark., 2014 ; Bing ve ark., 2013; Kükrer ve ark., 2015; Long ve ark., 2006; Zahra ve ark., 2014; Hou ve ark., 2013).

Tortum Gölü'nün etrafını çok dik yamaçların çevirmiş olmasından dolayı çevresinde yoğun yerleşim, şehirleşme, sanayileşme ve tarım alanı bulunmamaktadır. Bu özelliklerini de göz önünde bulundurarak Tortum Gölü yüzey sedimentlerindeki metal birikimlerinin ve bunlara bağlı gelişmiş olabilecek ekolojik risklerin indeksler yoluyla tespit edilmesi amaçlanmıştır. Yapılan değerlendirmelerin sağlıklı, tutarlı ve kapsamlı olabilmesi için çalışmada birbirinden farklı indeksler bir arada kullanılmıştır.

\section{Materyal ve Metot}

\section{Çalışma Alanı}

Tortum Gölü Erzurum iline bağlı Uzundere ilçesinde yer almakta olup, kuzeyindeki Kemerlidağ'da (2770 m) meydana gelen heyelanın Tortum Çayı vadisini doldurması sonucunda oluşmuş bir heyelan set gölüdür. Deniz seviyesinden yüksekliği $1012 \mathrm{~m}$ olan gölün kuzeydoğu-güneybatı doğrultusunda uzunluğu $8 \mathrm{~km}$, doğu-batı doğrultusunda ekseni $1,65 \mathrm{~km}$ ve alanı 6,6 $\mathrm{km}^{2}$,dir. Atalay (1988), gölün derinliğinin birbirinden farklı iki bölümden oluştuğunu ve bu iki bölümün 39 m'lik bir eşikle birbirinden ayrıldığını ifade etmiştir. Buna göre ilk bölüm, gölün güneydeki kıyı çizgisinin $1,5 \mathrm{~km}$ açığında olup yaklaşık olarak $78 \mathrm{~m}$ derinliktedir. İkinci bölüm ise Balıklı Mahallesi’nin açıklarına karşılık gelmekte olup $95 \mathrm{~m}$ derinliğindedir. Tortum gölü, havzada bulunan su kaynaklarından, eriyen kar sularından ve yağışlı evrelerde oluşarak göle ulaşan mevsimsel akışlardan beslenmektedir (Anonim, 2016). Çalışma alanını ve örnekleme istasyonları Şekil 1'de verilmiştir.

\section{Analitik Prosedürler}

Yüzey sedimentine ait örnekler Mayıs 2016'da örnekleme alanında seçilen altı istasyondan Van Veen Grab kullanılarak toplanmıştır. Homojenize edilerek plastik poşetlere konulan örnekler laboratuvarda asit ve RO saf su ile önceden yıkanmış petri kaplarına aktarılarak $60^{\circ} \mathrm{C}^{\prime} \mathrm{de} 24$ saat kurutulmuştur. Mortarla dövülerek toz haline getirilen örneklerde organik karbon (OC) analizleri Wakley-Black titrasyon yöntemiyle gerçekleştirilmiştir
(Gaudette ve ark., 1974). Çoklu element analizleri ACME analytical Labs, Kanada'da gerçekleştirilmiştir. Analizlerin kalite kontrolleri duplike ölçümler, kör örnekler ve standart referans materyal ölçümleri ile gerçekleştirilmiştir. ACME iç standart referans materyal analizinden elde edilen sonuçlar Tablo 1'de verilmiştir.

Sedimentteki metal birikimlerini tespit etmek için literatürde yaygın olarak Zenginleşme faktörü (EF) ve kontaminasyon faktörü (CF) olmak üzere iki yöntem kullanılmaktadır: Bunlar Zenginleşme faktörü (EF) ve kontaminasyon faktörüdür (CF). Zenginleşme faktörü güncel metal/Al oranının ardalan Metal/Al oranına bölünmesiyle elde edilir (Acevedo-Figueroa ve ark., 2006; Yilgor ve ark., 2012; Çevik ve ark., 2009; Vrhovnik ve ark.,2013). Bu sayede ardalan değerinin üzerine çıkan artışlar tespit edilerek antropojenik etkiyi belirlemek mümkün olmaktadır. Elde edilen değerler Sutherland (2000)'e göre değerlendirilmiştir. Buna göre $E F<2$ zenginleşme yok / minimal zenginleşmeyi, $\mathrm{EF}=2-5$ orta düzeyli zenginleşmeyi, $E F=5-20$ önemli zenginleşmeyi, $\mathrm{EF}=20-40$ çok yüksek zenginleşmeyi, $\mathrm{EF}>40$ aşırı derecede yüksek zenginleşmeyi ifade etmektedir.

Kontaminasyon faktörü ise Hakanson (1980)' e göre hesaplanmış ve değerlendirilmiştir: $\mathrm{CF}<1$ düşük kontaminasyon, $1 \leq \mathrm{CF}<3$ orta düzeyli kontaminasyon, $3 \leq \mathrm{CF}<6$ yüksek kontaminasyon, $\mathrm{CF}>6$ çok yüksek kontaminasyon olduğunu işaret etmektedir.

Sedimentin ağır metallere bağlı kalitesini belirlemek amacıyla kirlilik yük indeksi (PLI) hesaplanmıştır. CF kontaminasyon faktörünü, $\mathrm{n}$ ise kullanılan element sayısını ifade etmektedir (Suresh ve ark., 2011) :

$$
\mathrm{PLI}=\left(\mathrm{CF}_{1} \times \mathrm{CF}_{2} \times \ldots \mathrm{CF}_{\mathrm{n}}\right)^{1 / \mathrm{n}}
$$

Metallerin toksik etkileri hakkında çıkarımlar yapabilmek için Hakanson (1980) tarafından geliştirilen potansiyel ekolojik risk (PER) indeksi kullanılmıştır. Her bir metal için ayrı ayrı $\left(\operatorname{Er}^{i}\right)$ hesaplandığı gibi tüm metalleri içerecek şekilde bütünleşik olarak da hesaplanan risk faktörleri (PER) şu şekilde değerlendirilmektedir: $\mathrm{Er}^{\mathrm{i}}$ $<40$ düşük potansiyel ekolojik risk, $40 \leq \mathrm{Er}^{\mathrm{i}}<80$ orta düzeyli potansiyel ekolojik risk, $80 \leq \mathrm{Er}^{\mathrm{i}}<160$ önemli potansiyel ekolojik risk, $160 \leq \mathrm{Er}^{\mathrm{i}}<320$ yüksek potansiyel ekolojik risk, $\mathrm{Er}^{\mathrm{i}} \geq 320$ çok yüksek potansiyel ekolojik risk, PER < 150 düşük ekolojik risk, $150 \leq$ PER $<300$ orta düzeyli ekolojik risk, $300 \leq$ PER $<600$ önemli ekolojik risk, PER $\geq 600$ çok yüksek ekolojik risk.

Burada $\mathrm{Er}^{\mathrm{i}}$ ölçülen kontaminant için belirlenen ekolojik riski PER ise göl için hesaplanan bütünleşik ekolojik riski ifade etmektedir.

Metallerin kombine biyolojik etkileri Ortalama Olası Etki Konsantrasyonu Oranı (Mean Probable Effects Concentration Quotient, (mPEC-Q)) indeksine göre belirlendi (Long ve ark., 2006; Yang ve ark., 2014).

$$
\operatorname{mPEC}-\mathrm{Q}=\sum_{i=1}^{n}\left(\frac{C_{i}}{P E C_{i}}\right) / n
$$

Burada $\mathrm{C}_{\mathrm{i}}$ metal konsantrasyonunu, $\mathrm{PEC}_{\mathrm{i}}$ o metal için belirlenmiş muhtemel etki konsantrasyonunu, $\mathrm{n}$ ise toplam metal sayısını ifade etmektedir. 


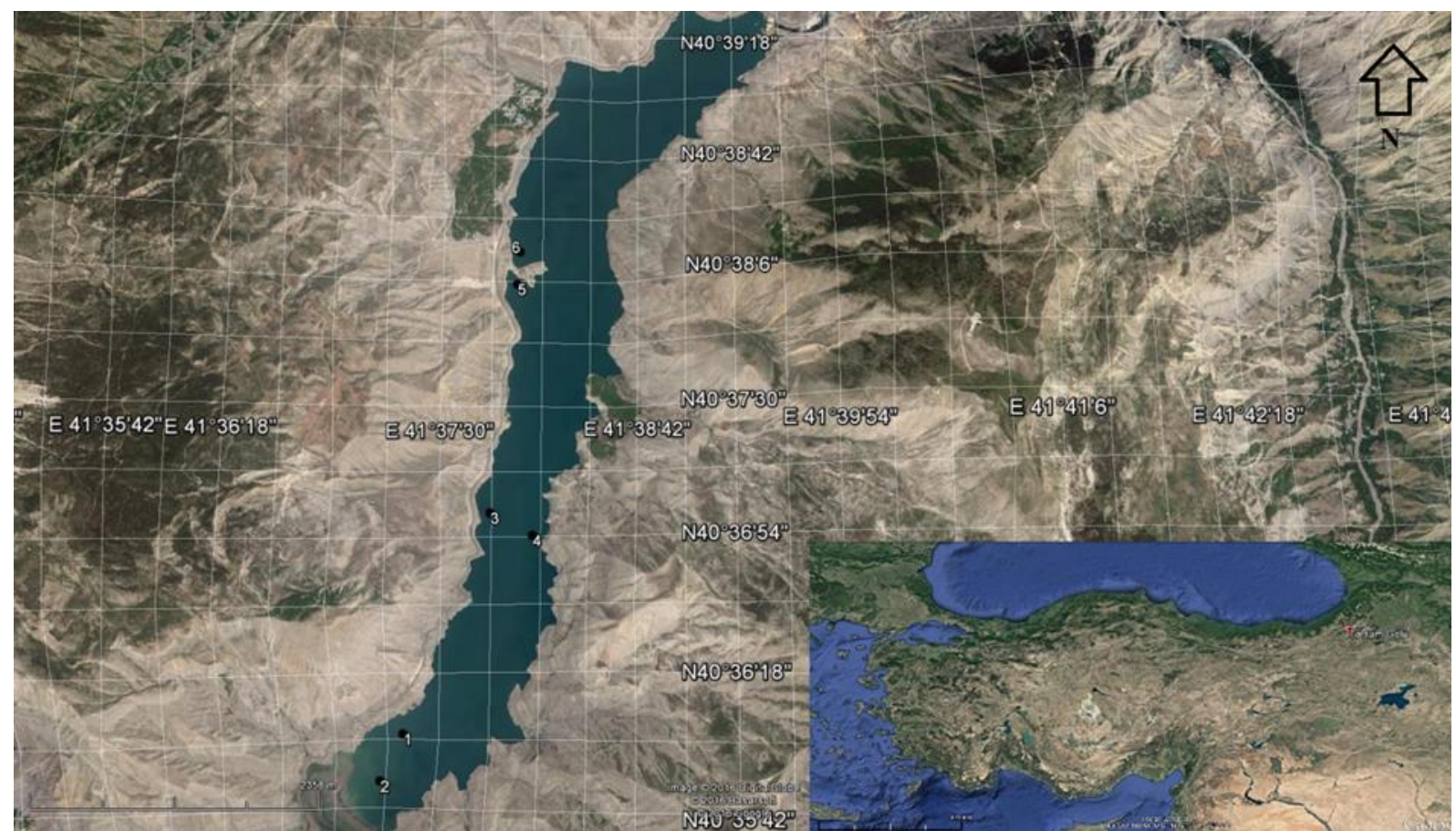

Şekil 1 Tortum Gölünün Konumu ve örnekleme istasyonları (Google Earth uygulamasından alınmıştır)

Tablo 1 ACME iç standart referans materyal analizinden elde edilen sonuçlar.

\begin{tabular}{l|ccc}
\hline \multicolumn{1}{c|}{ Element } & Gözlenen Değer & Beklenen Değer & Ölçüm Limitleri \\
\hline $\mathrm{Cu}(\mu \mathrm{g} / \mathrm{g})$ & 696,39 & 709 & 0.01 \\
$\mathrm{~Pb}(\mu \mathrm{g} / \mathrm{g})$ & 14,3 & 14,3 & 0.01 \\
$\mathrm{Zn}(\mu \mathrm{g} / \mathrm{g})$ & 30,7 & 31,4 & 0.1 \\
$\mathrm{Ni}(\mu \mathrm{g} / \mathrm{g})$ & 397,2 & 381 & 0.1 \\
$\mathrm{Mn}(\mu \mathrm{g} / \mathrm{g})$ & 379 & 400 & 1 \\
$\mathrm{Fe}(\%)$ & $\% 20,4$ & $\% 23,51$ & $\% 0,01$ \\
$\mathrm{As}(\mu \mathrm{g} / \mathrm{g})$ & 9,9 & 10,3 & 0.1 \\
$\mathrm{Cd}(\mu \mathrm{g} / \mathrm{g})$ & 0,03 & 0,03 & 0.01 \\
$\mathrm{Cr}(\mu \mathrm{g} / \mathrm{g})$ & 751,8 & 849 & 0.5 \\
$\mathrm{Al}(\%)$ & $\% 3,26$ & $\% 3,13$ & $\% 0,01$ \\
\hline
\end{tabular}

Aralarındaki anlamlı ilișkileri belirlemek amacıyla değişkenlere Pearson's korelasyon testi ve değişkenleri benzerliklerine göre gruplandırmak için kümelenme (cluster) analizi uygulanmıştır.

\section{Bulgular ve Tartışma}

\section{A ğır Metal Dă̆ılımları}

Ağır metal ve organik karbon değerlerinin istasyonlara göre dağılımları Tablo 2'de, tanımlayıcı istatistikleri Tablo 3'de verilmiştir. Metallerin ortalama bollukları $(\mu \mathrm{g} / \mathrm{g})$ sirasiyla: $\mathrm{Fe}>\mathrm{Al}>\mathrm{Mn}>\mathrm{Zn}>\mathrm{Cu}>\mathrm{Ni}>\mathrm{Cr}>\mathrm{As}>$ $\mathrm{Pb}>\mathrm{Cd}>\mathrm{Hg}$ şeklindedir. $\mathrm{Cd}$ hariç tüm metaller için en küçük değerler İst 6'da bulunmuştur. Cd için en düşük değer ise İst 2'de tespit edilmiştir. En büyük değerler ise $\mathrm{Pb}$ ve $\mathrm{Cd}$ hariç tüm metaller için İst 4'de belirlenmiştir. En büyük değer $\mathrm{Pb}$ için İst 3'de, $\mathrm{Cd}$ için İst 6'da bulunmuştur. $\mathrm{Cu}$ konsantrasyonu tüm istasyonlarda ardalan değerinin altında kalmıştır. Yüzey sedimentindeki metal konsantrasyonları ardalan değerleri ile karşılaştırıldığında, yüzey $\mathrm{Pb}$ konsantrasyonu ist. 2 ve ist. 6 hariç ardalan değerinin üstünde, $\mathrm{Zn}, \mathrm{Ni}, \mathrm{Fe}, \mathrm{Cr}, \mathrm{Al}$ konsantrasyonu ist. 4 hariç altında, Mn değerleri ist. 3 ve ist. 4 hariç altında, As değerleri ist. 1, ist. 3 ve ist. 4'de üzerinde, $\mathrm{Cd}$ konsantrasyonu ist 2 hariç üzerinde, $\mathrm{Hg}$ değeri ist. 3 ve ist. 5 hariç altında izlenmiştir. Tortum Gölü'nden elde edilen metal değerleri Türkiye'nin farklı bölgelerinde bulunan göllerle karşılaştırılmıştır (Tablo 4) . Buna göre, $\mathrm{Cu}$ değerleri Yedigöller'den düşük, Bafa Gölü'nün aralığına uygun, diğer göllerden yüksektir. Mn konsantrasyonu Bafa Gölü'nün aralığına uyumlu iken diğer göllerden yüksek bulunmuştur. Fe konsantrasyonu Yedigöller için verilen aralıkta ve diğer göllerden yüksek tespit edilmiştir. Tortum Gölü As seviyesi, verilen göller içinde arsenik ölçümü yapılmış iki gölden, Çıldır ve Işıklı göllerinden, fazladır. Cd seviyesi Çıldır ve Beyşehir göllerinden düşük, Işıklı ve Kovada gölleri için verilen aralıktadır. Hg seviyesi Bafa Gölü için verilen aralıkta, Beyşehir Gölü'nden düşük, Çıldır Gölü'nden yüksektir.

\section{Zenginlesme Faktörü (EF)}

Zenginleşme faktörü metallerin muhtemel kaynaklarını belirlemek, antropojenik etkiyi ve derecesini tespit etmek için sıklıkla başvurulan bir indekstir. Metallerin tane boyu farklılıklarına bağlı olarak değişen değerleri Al ile yapılan normalizasyonla giderilir. Bu sayede zenginleşme ile ilgili daha net bir sonuç elde edilir. Tortum Gölü'nde çalışılan metallerin ortalama 
zenginleşme faktörleri azalan sırayla $\mathrm{Cd}>\mathrm{As}>\mathrm{Pb}>\mathrm{Hg}>$ $\mathrm{Mn}>\mathrm{Ni}>\mathrm{Zn}=\mathrm{Fe}>\mathrm{Cr}>\mathrm{Cu}$ şeklindedir. Genel olarak en yüksek zenginleşme değerleri ist. 6 'da tespit edilmiştir. $\mathrm{Cu}$ değerleri ist. 1 ve ist. $6^{\prime}$ da minimal zenginleşme gösterirken, diğer istasyonlarda zenginleşme göstermemiştir. $\mathrm{Pb}$ ist. 6 'da orta dereceli zenginleşme gösterirken, ist 1,3 ve 5 de minimal zenginleşme tespit edilmiştir. $\mathrm{Zn}$ ist. 2 ve 5 'de $<1$ değerleri ile zenginleşme göstermezken, diğer istasyonlardaki zenginleşmesi ise minimal düzeydedir. Ni ist 1ve 6'da minimal zenginleşme sergilemiştir ve bunların dışında zenginleşmesi yoktur. Mn tüm istasyonlarda minimal düzeyde zenginleşme göstermektedir. Fe ist. 4 ve 5'de zenginleşme göstermezken, diğer istasyonlarda minimal artışlar yapmıştır. As tüm istasyonlarda minimal birikim göstermesine rağmen ist 6 'daki brikimi orta dereceli zenginleşme sınırına çok yakındır. Cd ist. 6 hariç minimal birikim sergilerken, bu istasyonda belirgin derecede fazla bir birikim sergilemektedir. $\mathrm{Cr}$ ve $\mathrm{Hg}$ elementleri de genel olarak kayda değer artışlar göstermezlerken, en dikkat çekici artış Hg için ist. 6'da gözlenmiştir (Tablo 5). Bu artışlar antropojenik kökenli girdileri işaret etmektedir ve ekosistem sağlığı için dikkat edilmesi gereken bir durumdur.

Tablo 2 Metal $(\mu \mathrm{g} / \mathrm{g})$ ve \% organik karbon dağılımları.

\begin{tabular}{c|cccccccccccc}
\hline$\dot{\mathrm{I}}$ & $\mathrm{Cu}$ & $\mathrm{Pb}$ & $\mathrm{Zn}$ & $\mathrm{Ni}$ & $\mathrm{Mn}$ & $\mathrm{Fe}$ & $\mathrm{As}$ & $\mathrm{Cd}$ & $\mathrm{Cr}$ & $\mathrm{Al}$ & $\mathrm{Hg}$ & $\%$ Org Karbon \\
\hline 1 & 44,95 & 9,12 & 78,1 & 36,8 & 738 & 34100 & 23,6 & 0,17 & 27,7 & 21500 & 0,075 & 0,339 \\
2 & 35,33 & 6,23 & 63,7 & 27 & 636 & 31100 & 19,2 & 0,12 & 22,7 & 19400 & 0,054 & 0,144 \\
3 & 46,07 & 9,87 & 83,7 & 38 & 858 & 34200 & 24,3 & 0,2 & 29,3 & 23800 & 0,087 & 0,000 \\
4 & 49,14 & 8,55 & 96,5 & 39,5 & 930 & 38600 & 26,7 & 0,21 & 33,3 & 27700 & 0,078 & 0,297 \\
5 & 42,58 & 9,52 & 78,6 & 32,6 & 747 & 31400 & 20,5 & 0,18 & 25,9 & 23200 & 0,084 & 0,342 \\
6 & 23,11 & 6,31 & 39,1 & 20,5 & 349 & 12800 & 14,3 & 0,22 & 10,7 & 8900 & 0,051 & 0,578 \\
\hline
\end{tabular}

Tablo 3 Değişskenlere ait tanımlayıcı istatistikler

\begin{tabular}{l|cccccccccccccc}
\hline & $\mathrm{Cu}$ & $\mathrm{Pb}$ & $\mathrm{Zn}$ & $\mathrm{Ni}$ & $\mathrm{Mn}$ & $\mathrm{Fe}$ & $\mathrm{As}$ & $\mathrm{Cd}$ & $\mathrm{Cr}$ & $\mathrm{Al}$ & $\mathrm{Hg}$ & PER & PLI & OC \\
\hline Ort & 40,20 & 8,27 & 73,28 & 32,40 & 709,67 & 30366,70 & 21,43 & 0,18 & 24,93 & 20750,00 & 0,07 & 98,20 & 0,08 & 0,28 \\
$\mathrm{SS}$ & 9,57 & 1,61 & 19,80 & 7,37 & 204,09 & 9017,91 & 4,41 & 0,04 & 7,81 & 6425,18 & 0,02 & 15,75 & 0,09 & 0,20 \\
$\mathrm{SH}$ & 3,91 & 0,66 & 8,08 & 3,01 & 83,32 & 3681,55 & 1,80 & 0,01 & 3,19 & 2623,07 & 0,01 & 6,43 & 0,04 & 0,08 \\
$\mathrm{EK}$ & 23,11 & 6,23 & 39,10 & 20,50 & 349,00 & 12800,00 & 14,30 & 0,12 & 10,70 & 8900,00 & 0,05 & 73,07 & 0,00 & 0,00 \\
$\mathrm{~EB}$ & 49,14 & 9,87 & 96,50 & 39,50 & 930,00 & 38600,00 & 26,70 & 0,22 & 33,30 & 27700,00 & 0,09 & 113,32 & 0,24 & 0,58 \\
$\mathrm{~A}$ & 51,6 & 8,26 & 89,2 & 39,3 & 823 & 36000 & 20,8 & 0,15 & 30,4 & 25800 & 0,08 & - & - & - \\
\hline
\end{tabular}

Ort: Ortalama, SS: Standart sapma, SH: Standart Hata, EK: En küçük, EB: En büyük, A: Ardalan

Tablo 4 Sedimentteki metal konsantrasyonlarının $(\mu \mathrm{g} / \mathrm{g})$ Türkiye'deki bazı göllerden elden edilen değerlerle karşılaştırılması.

\begin{tabular}{|c|c|c|c|c|c|c|c|c|c|c|c|}
\hline Göl & $\mathrm{Cu}$ & $\mathrm{Pb}$ & $\mathrm{Zn}$ & $\mathrm{Ni}$ & $\mathrm{Mn}$ & $\mathrm{Fe}$ & As & $\mathrm{Cd}$ & $\mathrm{Cr}$ & $\mathrm{Al}$ & $\mathrm{Hg}$ \\
\hline$\overline{\mathrm{BE}}$ & - & 32,65 & - & - & - & - & - & 13,05 & 10,63 & - & 0,24 \\
\hline IŞ & $\begin{array}{l}2,68- \\
38,84\end{array}$ & - & $\begin{array}{l}16,34- \\
159,56\end{array}$ & $\begin{array}{l}11,23- \\
211,16\end{array}$ & $\begin{array}{l}238,4- \\
683,62\end{array}$ & $\begin{array}{l}17,22- \\
25475\end{array}$ & $\begin{array}{l}1,14- \\
16,33\end{array}$ & $\begin{array}{c}0,09- \\
3,06\end{array}$ & $\begin{array}{l}11,60- \\
269,6\end{array}$ & - & - \\
\hline KA & $\mathrm{LA}^{*}$ & $\begin{array}{l}\text { LA- } \\
0,003\end{array}$ & $\begin{array}{c}0,019- \\
0,033\end{array}$ & - & $\begin{array}{c}0,305- \\
0,558\end{array}$ & $\begin{array}{l}7430- \\
14680\end{array}$ & & LA & $\begin{array}{c}0,041- \\
0,125\end{array}$ & $\begin{array}{c}3,314- \\
1068\end{array}$ & LA \\
\hline HA & $\begin{array}{l}10- \\
64\end{array}$ & LA & $\begin{array}{l}46- \\
210\end{array}$ & $\begin{array}{l}38- \\
130\end{array}$ & $\begin{array}{l}85- \\
625\end{array}$ & $\begin{array}{l}3650- \\
30000\end{array}$ & - & - & $\begin{array}{l}17- \\
79\end{array}$ & & - \\
\hline MO & 15,13 & 0,822 & 13,786 & - & 125,668 & 3577 & - & - & 28,55 & - & - \\
\hline $\mathrm{KO}$ & $\begin{array}{l}4,65- \\
13,77\end{array}$ & $\begin{array}{c}1,74- \\
4,42\end{array}$ & $\begin{array}{l}12,82- \\
33,42\end{array}$ & $\begin{array}{l}9,13- \\
25,93\end{array}$ & $\begin{array}{l}61,19- \\
165,96\end{array}$ & $\begin{array}{l}3006- \\
7345\end{array}$ & - & $\begin{array}{l}\text { LA- } \\
0,27\end{array}$ & $\begin{array}{l}6,63- \\
17,59\end{array}$ & $\begin{array}{c}3780- \\
9990\end{array}$ & - \\
\hline YED & $\begin{array}{l}67,8- \\
68,53\end{array}$ & $\begin{array}{c}30,67- \\
32,67\end{array}$ & $\begin{array}{l}68,47- \\
104,13\end{array}$ & $\begin{array}{c}59,87- \\
60,33\end{array}$ & $\begin{array}{c}466,8- \\
510,8\end{array}$ & $\begin{array}{l}18303- \\
48701\end{array}$ & & LA & $\begin{array}{l}43,2- \\
43,93\end{array}$ & $\begin{array}{c}11572,2- \\
13705,6\end{array}$ & LA \\
\hline ÇI & 20,34 & 11,14 & 49,18 & 30,20 & 478,67 & 15767 & 3,45 & 0,22 & 27,62 & & 0,06 \\
\hline AT & $\begin{array}{c}14,57- \\
22,7\end{array}$ & LA & $\begin{array}{c}59,14- \\
60,79\end{array}$ & $\begin{array}{l}43,69- \\
139,69\end{array}$ & $\begin{array}{c}73,6- \\
514,07\end{array}$ & $\begin{array}{c}12587- \\
19265\end{array}$ & & LA & & & ND \\
\hline B & $\begin{array}{c}5,79- \\
55,1\end{array}$ & $\begin{array}{l}2,31- \\
23,5\end{array}$ & $\begin{array}{c}26,62- \\
79,9\end{array}$ & $\begin{array}{c}1,21- \\
320\end{array}$ & $\begin{array}{c}250- \\
780\end{array}$ & $\begin{array}{c}9,38- \\
33,1(\mathrm{~g} / \mathrm{kg})\end{array}$ & - & - & $\begin{array}{l}63,1- \\
277\end{array}$ & - & $\begin{array}{r}0,013- \\
0,260\end{array}$ \\
\hline $\mathrm{T}$ & 40,20 & 8,27 & 73,28 & 32,40 & 709,67 & 30366,7 & 21,43 & 0,18 & 24,93 & 20750 & 0,07 \\
\hline
\end{tabular}

BE: Beyșehir (Kaynak: Altındağ ve Yiğit 2005), IȘ: Ișıklı (Kaynak: Tekin-Özan, ve Aktan 2012), KA: Karacaören II (Kaynak: Kır ve Tumantozlu 2012), HA: Hazar (Kaynak: Özmen ve ark., 2004), MO: Mogan (Kaynak: Benzer ve ark., 2013), KO: Kovada (Kaynak: Kır ve ark., 2007), YED: Yedigöller (Kütahya) (Kaynak: Arslan ve ark., 2011 ), ÇI: Çıldır (Kaynak: Kükrer ve ark., 2014), AT: Atatürk Dam Lake (Kaynak: Karadede ve Ünlü 2000), B: Bafa (Yilgor ve ark., 2012), T: Tortum (Bu çalışma), LA: Ölçüm limitlerinin altında

Tablo 5 Tortum Gölü'nde ölçülen metallerin zenginleşme faktörleri.

\begin{tabular}{c|cccccccccc}
\hline $\mathrm{EF}$ & $\mathrm{Cu}$ & $\mathrm{Pb}$ & $\mathrm{Zn}$ & $\mathrm{Ni}$ & $\mathrm{Mn}$ & $\mathrm{Fe}$ & $\mathrm{As}$ & $\mathrm{Cd}$ & $\mathrm{Cr}$ & $\mathrm{Hg}$ \\
\hline 1 & 1,05 & 1,32 & 1,05 & 1,12 & 1,08 & 1,14 & 1,36 & 1,36 & 1,09 & 1,13 \\
2 & 0,91 & 1,00 & 0,95 & 0,91 & 1,03 & 1,15 & 1,23 & 1,06 & 0,99 & 0,90 \\
3 & 0,97 & 1,30 & 1,02 & 1,05 & 1,13 & 1,03 & 1,27 & 1,45 & 1,04 & 1,18 \\
4 & 0,89 & 0,96 & 1,01 & 0,94 & 1,05 & 1,00 & 1,20 & 1,30 & 1,02 & 0,91 \\
5 & 0,92 & 1,28 & 0,98 & 0,92 & 1,01 & 0,97 & 1,10 & 1,33 & 0,95 & 1,17 \\
6 & 1,30 & 2,21 & 1,27 & 1,51 & 1,23 & 1,03 & 1,99 & 4,25 & 1,02 & 1,85 \\
\hline
\end{tabular}




\section{Kontaminasyon Faktörü (CF)}

Metallerin kaynaklarıyla ilgili tahmin yapabilmek için kullanılan bir indeks olan CF değerleri azalan sırayla şöyle sıralanmıştır: $\mathrm{Cd}>\mathrm{As}>\mathrm{Pb}>\mathrm{Hg}>\mathrm{Mn}>\mathrm{Fe}>\mathrm{Ni}=\mathrm{Zn}$ $=\mathrm{Cr}>\mathrm{Al}>\mathrm{Cu}$. $\mathrm{CF}$ değerlerine göre $\mathrm{Cu}$ için tüm istasyonlarda düşük birikim gözlenmiştir. $\mathrm{Pb}$ için ist. 2 ve 6 hariç orta düzeyli kontaminasyon, bu iki istasyon için düşük kontaminasyon tespit edilmiştir. $\mathrm{Zn}, \mathrm{Ni}, \mathrm{Fe}, \mathrm{Cr}$ ve Al sadece ist 4'de orta düzeyli birikim göstermiş diğer istasyonlarda değerler $<1$ olmuştur. Mn ist. 3 ve 4'de, As ist. 1,3 ve 4 'de, $\mathrm{Hg}$ ise yalnızca ist 5 'de sinır değer olan l'i aşarak orta düzeyli kontaminasyon göstermişlerdir. Tüm metaller bazı istasyonlarda orta düzey kontaminasyon aralığına ulaşmış olsalar da CF değerlerinin düşük ve orta kontaminasyon arasındaki sınıra yakın olduğunu ve çok ciddi boyutlarda olmadığını belirtmek gerekir (Tablo 6).

\section{Kirlilik Yük İndeksi (PLI)}

PLI değerleri Tablo 7'de sunulmuştur. Hesaplanan PLI değerleri 0,00 ile 0,24 arasındadır. Ortalama değer ise 0,08'dir. Suresh ve ark. (2011) PLI için ideal değerin sıfir olduğunu ve bunun ortamda kirlilik bulunmadığının göstergesi olduğunu, değerin 1'i aşmasının ise ilerleyen kirliliğe işaret ettiğini belirtmişlerdir. Tortum Gölü'nde değerlerin sıfıra yakın seviyelerde bulunması PLI 'ya göre sedimentte kirlilik tespit edilmediği anlamına gelmektedir.

\section{Potansiyel Ekolojik Risk}

Potansiyel ekolojik risk indeksi hem her bir metal için ayrı ayrı, hem de bütün metallerin toplam potansiyel etkisini ortaya koyacak şekilde entegre olarak hesaplanmıș ve değerlendirilmiștir (Tablo 7). Metallerin hesaplanan risk indekslerine göre sıralama şöyledir: $\mathrm{Cd}>$ $\mathrm{Hg}>\mathrm{As}>\mathrm{Pb}>\mathrm{Ni}>\mathrm{Cu}>\mathrm{Cr}>\mathrm{Zn}$. Metallerin ayrı ayrı değerlendirmeleri yapıldığında hiç bir metalin ekolojik risk indeksi ortalaması sınır değer olan 40'ı aşmamaktadır ve düşük ekolojik riske işaret etmektedir. İstasyonlara göre bakıldığında ise $\mathrm{Cd}$ ve $\mathrm{Hg}$ hariç tüm metaller tüm istasyonlarda düşük risk göstermektedir. $\mathrm{Cd}$ ist. 3,4 ve 6 'da, $\mathrm{Hg}$ ise ist. 3 ve 5'de sınır değerin çok az üstüne çıkarak orta dereceli ekolojik risk göstermektedir ancak bu risklerin ciddi seviyelere ulaşmadığı söylenebilir. Genel olarak metallerin maksimum ekolojik risk değerleri ist. 3 ve ist. 4'de tespit edilmiştir. Metallerin entegre potansiyel ekolojik risklerine göre (PER) en yüksek değer ist. 3'de tespit edilmiş ve bunu çok yakın sayısal ifadeyle ist. 4 izlemiştir. En düşük PER değeri ise ist 2 için tespit edilmiştir. Entegre değerlendirmede PER değeri hiç bir istasyon için >150 olmadığından ekolojik risklerin düșük olduğu tespit edilmiştir.

Ortalama Olası Etki Konsantrasyonu Oranı (mPEC-Q)

Metallerin muhtemel karma biyolojik etkilerinin belirlenmesi amaciyla uygulanan bu indekse göre en yüksek değer ist. 4'de, en düşük değer ise ist. 6'da tespit edilmiştir (Tablo 7). Ortalama mPEC-Q ise 0,27'dir. Tortum gölünde çalıșılan istasyonların tümü düşük-orta öncelikli alan sınıfına girmektedir ve gölde metallerin toksik olma olasılığg \% 15-29 aralığındadır. (Long ve ark., 2006; Yang ve ark., 2014).

\section{Çok Değişkenli İstatistiksel Analizler}

Pearson's korelasyon analizi: Değişkenlerin birbirleriyle olan ilişkilerini belirlemek için yapılan Pearson's korelasyon testi sonuçlarına göre bir çok metal birbiriyle ilişkili olmasına rağmen $\mathrm{Cd}$ hiç bir metalle korelasyon göstermemiştir. Fe ile $\mathrm{Mn}, \mathrm{Pb}$ ve $\mathrm{Cd}$ hariç bütün metallerle, $\mathrm{Al}$ ise $\mathrm{Pb}, \mathrm{Cd}$ ve $\mathrm{Hg}$ hariç tüm metallerle yüksek korelasyon göstermektedir. Buna göre $\mathrm{Pb}$ ve $\mathrm{Cd}$ elementlerinin taşınma mekanizmalarının diğer elementlerden farklı olduğu, birçok elementin ise $\mathrm{Fe} / \mathrm{Mn}$ bileşikleri ve aluminosilikatlara tutunarak geldiği anlaşılmaktadır. PER'e en büyük katkı $\mathrm{Pb}$, Ni ve $\mathrm{Hg}$ elementlerinden gelirken, PLI'ya önemli katk1 yapan elementler $\mathrm{Zn}$ ve As'tır. Ayrıntılı karşılatırmalar için korelasyonlar Tablo 8.'de verilmiştir.

Kümelenme (Cluster) analizi: Değişkenlerin birbirleriyle olan ilişkilerini ve kümelenmelerini görmek amacıyla verilere kümelenme analizi uygulanmıştır. Kümelenme dendogramına göre iki büyük kümelenme dikkat çekmektedir (Şekil 2). Birinci grup $\mathrm{Cu}, \mathrm{Zn}, \mathrm{Mn}, \mathrm{Cr}$, $\mathrm{Al}, \mathrm{Ni}$, As ve Fe içermektedir ve bu elementlerin taşınım mekanizmalarının ve/veya kaynaklarının benzer olduğunu ifade etmektedir. İkinci grup ise $\mathrm{Pb}, \mathrm{Hg}$ ve $\mathrm{PER}$ 'den oluşmaktadır ve bu iki elementin PER'e katkılarını ve muhtemel ortak kaynaklarını/süreçlerini temsil etmektedir. $\mathrm{Cd}$ ve $\mathrm{OC}$ ise bu iki gruptan daha uzağa konumlanmaktadır.

Tablo 6 Tortum Gölü'nde ölçülen metallerin kontaminasyon faktörleri

\begin{tabular}{c|ccccccccccccccc}
\hline $\mathrm{CF}$ & $\mathrm{Cu}$ & $\mathrm{Pb}$ & $\mathrm{Zn}$ & $\mathrm{Ni}$ & $\mathrm{Mn}$ & $\mathrm{Fe}$ & $\mathrm{As}$ & $\mathrm{Cd}$ & $\mathrm{Cr}$ \\
\hline 1 & 0,87 & 1,10 & 0,88 & 0,94 & 0,90 & 0,95 & 1,13 & 1,13 & 0,91 & 0,83 & 0,94 \\
2 & 0,68 & 0,75 & 0,71 & 0,69 & 0,77 & 0,86 & 0,92 & 0,80 & 0,75 & 0,75 & 0,68 \\
3 & 0,89 & 1,19 & 0,94 & 0,97 & 1,04 & 0,95 & 1,17 & 1,33 & 0,96 & 0,92 & 1,09 \\
4 & 0,95 & 1,04 & 1,08 & 1,01 & 1,13 & 1,07 & 1,28 & 1,40 & 1,10 & 1,07 & 0,98 & 0,07 \\
5 & 0,83 & 1,15 & 0,88 & 0,83 & 0,91 & 0,87 & 0,99 & 1,20 & 0,85 & 0,90 & 1,05 \\
6 & 0,45 & 0,76 & 0,44 & 0,52 & 0,42 & 0,36 & 0,69 & 1,47 & 0,35 & 0,34 & 0,64 \\
\hline
\end{tabular}

Tablo 7 Tortum Gölü'nde ölçülen metallere ait potansiyel ekolojik risk indeksi, kirlilik yük indeksi ve mPEC-Q değerleri.

\begin{tabular}{|c|c|c|c|c|c|c|c|c|c|c|c|}
\hline & $\mathrm{Cu}$ & $\mathrm{Pb}$ & $\mathrm{Zn}$ & $\mathrm{Ni}$ & As & $\mathrm{Cd}$ & $\mathrm{Cr}$ & $\mathrm{Hg}$ & PER & PLI & mPEC-Q \\
\hline 1 & 4,36 & 5,52 & 0,88 & 4,68 & 11,35 & 34,00 & 1,82 & 37,50 & 100,10 & 0,06 & 0,30 \\
\hline 2 & 3,42 & 3,77 & 0,71 & 3,44 & 9,23 & 24,00 & 1,49 & 27,00 & 73,07 & 0,00 & 0,23 \\
\hline 3 & 4,46 & 5,97 & 0,94 & 4,83 & 11,68 & 40,00 & 1,93 & 43,50 & 113,32 & 0,13 & 0,31 \\
\hline 4 & 4,76 & 5,18 & 1,08 & 5,03 & 12,84 & 42,00 & 2,19 & 39,00 & 112,07 & 0,24 & 0,33 \\
\hline 5 & 4,13 & 5,76 & 0,88 & 4,15 & 9,86 & 36,00 & 1,70 & 42,00 & 104,48 & 0,05 & 0,27 \\
\hline 6 & 2,24 & 3,82 & 0,44 & 2,61 & 6,88 & 44,00 & 0,70 & 25,50 & 86,18 & 0,00 & 0,17 \\
\hline
\end{tabular}


Tablo 8 Değişkenler arasındaki Pearson korelasyon katsayıları (koyu renkli ifadeler \%95 güven aralığında istatistiksel olarak önemli korelasyonları ifade etmektedir.)

\begin{tabular}{|c|c|c|c|c|c|c|c|c|c|c|c|c|c|c|}
\hline & $\mathrm{Cu}$ & $\mathrm{Pb}$ & $\mathrm{Zn}$ & $\mathrm{Ni}$ & $\mathrm{Mn}$ & $\mathrm{Fe}$ & As & $\mathrm{Cd}$ & $\mathrm{Cr}$ & $\mathrm{Al}$ & $\mathrm{Hg}$ & PER & PLI & $\mathrm{OC}$ \\
\hline $\mathrm{Cu}$ & 1 & $*$ & $*$ & $*$ & $*$ & $*$ & $*$ & $*$ & $*$ & $*$ & $*$ & $*$ & $*$ & * \\
\hline $\mathrm{Pb}$ & 0,809 & 1 & $*$ & * & $*$ & * & $*$ & * & * & $*$ & * & * & * & * \\
\hline $\mathrm{Zn}$ & 0,986 & 0,756 & 1 & $*$ & $*$ & $*$ & $*$ & $*$ & $*$ & $*$ & $*$ & $*$ & $*$ & $*$ \\
\hline $\mathrm{Ni}$ & $\mathbf{0 , 9 8 3}$ & $\mathbf{0 , 8 3 1}$ & 0,964 & 1 & $*$ & $*$ & $*$ & $*$ & $*$ & $*$ & $*$ & $*$ & $*$ & $*$ \\
\hline $\mathrm{Mn}$ & $\mathbf{0 , 9 8 1}$ & 0,747 & $\mathbf{0 , 9 9 1}$ & $\mathbf{0 , 9 5 9}$ & 1 & * & $*$ & * & * & $*$ & $*$ & $*$ & $*$ & * \\
\hline $\mathrm{Fe}$ & 0,956 & 0,632 & 0,950 & 0,907 & $\mathbf{0 , 9 5 7}$ & 1 & $*$ & $*$ & $*$ & $*$ & $*$ & $*$ & $*$ & $*$ \\
\hline As & 0,969 & 0,712 & 0,968 & 0,981 & 0,965 & $\mathbf{0 , 9 3 0}$ & 1 & $*$ & $*$ & $*$ & $*$ & $*$ & $*$ & $*$ \\
\hline $\mathrm{Cd}$ & $-0,030$ & 0,261 & 0,018 & 0,096 & $-0,019$ & $-0,282$ & 0,053 & 1 & $*$ & $*$ & $*$ & $*$ & $*$ & * \\
\hline $\mathrm{Cr}$ & 0,989 & 0,721 & 0,990 & 0,963 & 0,991 & $\mathbf{0 , 9 8 0}$ & 0,975 & $-0,088$ & 1 & $*$ & $*$ & $*$ & $*$ & $*$ \\
\hline $\mathrm{Al}$ & 0,970 & 0,706 & 0,987 & 0,922 & 0,986 & 0,971 & 0,932 & $-0,112$ & 0,986 & 1 & $*$ & $*$ & $*$ & $*$ \\
\hline $\mathrm{Hg}$ & $\mathbf{0 , 8 5 8}$ & 0,981 & $\mathbf{0 , 8 3 2}$ & 0,864 & $\mathbf{0 , 8 2 8}$ & 0,702 & 0,767 & 0,252 & 0,791 & 0,795 & 1 & $*$ & $*$ & $*$ \\
\hline PER & 0,748 & $\mathbf{0 , 8 8 7}$ & 0,753 & 0,812 & 0,732 & 0,533 & 0,738 & 0,606 & 0,683 & 0,663 & 0,906 & 1 & $*$ & $*$ \\
\hline PLI & 0,753 & 0,528 & $\mathbf{0 , 8 2 2}$ & 0,798 & 0,807 & 0,663 & 0,848 & 0,457 & 0,777 & 0,756 & 0,625 & 0,790 & 1 & $*$ \\
\hline $\mathrm{OC}$ & $-0,583$ & $-0,393$ & $-0,554$ & $-0,550$ & $-0,654$ & $-0,675$ & $-0,568$ & 0,403 & $-0,624$ & $-0,615$ & $-0,462$ & $-0,236$ & $-0,302$ & 1 \\
\hline
\end{tabular}

\section{Sonuç}

Tortum Gölü'nde seçilen altı istasyondan toplanan sediment örneklerinde ağır metal içerikleri ve bunların yaratabileceği potansiyel ekolojik riskler çalışıldı. Metallerin zenginleşme ve kontaminasyon faktörlerine göre minimal-orta düzeyde birikim gösterdikleri tespit edildi. Her bir metal için hesaplanan ekolojik risk değerleri $\mathrm{Hg}$ ve $\mathrm{Cd}$ için bazı istasyonlarda aşılsa da genel olarak sınır değerlerin altında tespit edilmiştir. Bütünleşik PER değeri ise tüm istasyonlarda düşük riske işaret etmiştir. Tüm bu değerlendirmelerden sonra Tortum Gölü'nde çalışılan metallerin şu anda ekosistem için risk oluştura bilecek konsantrasyonlarda bulunmadığı sonucuna varılmıştır. En yüksek ekolojik risk değerine sahip olan Cd'nin diğer elementlerle ilişkisinin bulunmaması ekosisteme farklı yollardan ulaştığını düşündürmektedir. Şu an için sınır seviyelerde olan $\mathrm{Cd}$ ve $\mathrm{Hg}$ konsantrasyonlarının artmaması ve ekosistemin korunması gölün geleceği açısından önem arz etmektedir.

\section{Teşekkür}

Çalışmaya sağladığı destekten ötürü Ardahan Üniversitesi Bilimsel Araştırma Projeleri Koordinatörlüğüne (Proje no: 2015-13), arazi çalışmalarındaki yardımlarından ötürü Dr. İsmail Onur Tunç, Dr. Çağlar Çakır ve Arş. Gör. Abdullah Akbaş'a teşekkür ederim.

\section{Kaynaklar}

Acevedo-Figueroa D, Jime'nez BD, Rodr1'guez-Sierra CJ. 2006. Trace metals in sediments of two estuarine lagoons from Puerto Rico. Environmental Pollution, 141: 336-342. DOI: 10.1016/j.envpol.2005.08.037.

Altındağ A, Yiğit S. 2005. Assessment of heavy metal concentrations in the food web of lake Beysşehir, Turkey. Chemosphere 60: 552-556. DOI: 10.1016/j.chemosphere. 2005.01.009.

Anonim. 2016. Tortum gölü'nün paleoiklimsel proksiler açısından incelenmesi. Ardahan Üniversitesi Bilimsel Araştırma Projeleri Koordinatörlüğü. Proje raporu.

Arslan N, Tokatlı C, Çiçek A, Köse E. 2011. Yedigöller (Kütahya) bölgesinde su ve sediment örneklerinde bazı metal seviyelerinin belirlenmesi. Review of Hydrobiology, 4,1: 17-28.
Atalay İ. 1988. "The Geography of Lake Tortum District (Northeastern Anatolia)". Ege Coğrafya Dergisi, 4: 19-40.

Benzer S, Arslan H, Uzel N, Gül A, Yılmaz M. 2013. Concentrations of metals in water, sediment and tissues of Cyprinus carpio L., 1758 from Mogan Lake (Turkey). Iranian Journal of Fisheries Sciences, 12(1): 45-55.

Bing H, Wu Y, Liu E, Yang X. 2013. Assessment of heavy metal enrichment and its human impact in lacustrine sediments from four lakes in the mid-low reaches of the Yangtze River, China. Journal of Environmental Sciences , 25(7) :1300-1309. DOI: 10.1016/s1001-0742(12)60195-8.

Cheng H, Li M, Zhao C, Yang K, Li K, Peng M, Yang Z, Liu F, Liu Y, Bai R, Cui Y, Huang Z, Li L, Liao Q, Luo J, Jia S, Pang X, Yang J, Yin G. 2015. Concentrations of toxic metals and ecological risk assessment for sediments of major freshwater lakes in China. J. Geochem. Explor., 157: 15-26. DOİ: 10.1016/j.gexplo.2015.05.010.

Çevik F, Göksu MZL, Derici OB, Fındık Ö. 2009. An assessment of metal pollution in surface sediments of Seyhan dam by using enrichment factor, geoaccumulation index and statistical analyses. Environmental Monitoring and Assessment, 152: 309-317.

Gaudette HE, Flight WR, Toner L, Folger W. 1974. An inexpensive titration method for the determination of organic carbon in recent sediments. Journal of Sedimentary Petrology, 44: 249-253.

Hakanson L. 1980. Ecological risk index for aquatic pollution control, a sedimentological approach. Water Research, 14: 975-1001. DOI: 10.1016/0043-1354(80)90143-8.

Hou D, He J, Lü C, Ren L, Fan Q, Wang J, Xie Z. 2013. Distribution characteristics and potential ecological risk assessment of heavy metals $(\mathrm{Cu}, \mathrm{Pb}, \mathrm{Zn}, \mathrm{Cd})$ in water and sediments from Lake Dalinouer, China. Ecotoxicology and Environmental Safety, 93: 135-144. DOI:10.1016/j.ecoenv. 2013.03.012.

Karadede H, Ünlü E. 2000. Concentrations of some heavy metals in water, sediment and fish species from the Atatürk Dam Lake (Euphrates), Turkey. Chemosphere, 41: 13711376. DOI: 10.1016/s0045-6535(99)00563-9.

Kır İ, Tekin Özan S, Tuncay Y. 2007. Kovada Gölü'nün Su ve Sedimentindeki Bazı Ağır Metallerin Mevsimsel Değişimi. E.Ü Su Ürünleri Dergisi 24(1-2): 155-158.

Kır I, Tumantozlu H. 2012. Karacaören-II Baraj Gölü'ndeki Su, Sediment ve Sazan (Cyprinus carpio) Örneklerinde Bazı Ağır Metal Birikiminin İncelenmesi. Ekoloji 21, 82: 65-70. DOI: 10.5053/ekoloji.2011.829. 
Kükrer S, Şeker S, Abacı ZT, Kutlu B. 2014. Ecological risk assessment of heavy metals in surface sediments of northern littoral zone of Lake Çıldır, Ardahan, Turkey. Environmental Monitoring and Assessment, 186: $3847-$ 3857. DOI: 10.1007/s10661-014-3662-4.

Kükrer S, Erginal AE, Şeker S, Karabıyıkoğlu M. 2015. Distribution and environmental risk evaluation of heavy metal in core sediments from Lake Çıldır (NE Turkey). Environ Monit Assess., 187:453 DOI 10.1007/s10661-0154685-1

Long ER, Ingersoll C, MacDonald DD. 2006.Calculation and uses of mean sediment quality guideline quotients :acritical review. Environ.Sci.Technol., 40: 1726-1736. DOI: 10.1021/es058012d.

Mutlu E, Tepe AY. 2014. Yayladağı Sulama Göleti (Hatay) Suyunun Bazı Fiziksel ve Kimyasal Özelliklerinin İncelenmesi. Alınteri Zirai Bilimler Dergisi, 27(B): 18-23.

Mutlu E, Kutlu B, Yanık T, Demir T. 2014. Evaluation of water quality of Karacalar Dam (Ulaş-Sivas) By using Physicochemical methods. Journal of Selçuk University Natural and Applied Science, ICOEST 2014 Özel sayı: 30-40.

Nriago JO, Pacyna J.M. 1988. Quantitative assessment of worldwide contamination of air, water and soils by trace metals. Nature, 333: 134-140. DOI: 10.1038/333134a0 .

Özmen H, Külahçı F, Çukurovalı A, Doğru M. 2004 Concentrations of heavy metal and radioactivity in surface water and sediment of Hazar Lake (Elazı̆g, Turkey). Chemosphere, 55: 401-408.DOI: 10.1016/j.chemosphere. 2003.11.003.

Suresh G, Ramasamy V, Meenakshisundaram V, Venkatachalapathy R, Ponnusamy V. 2011. Influence of mineralogical and heavy metal composition on natural radionuclide contents in the river sediments. Applied Radiation and Isotopes, 69: 1466-1474. DOI: 10.1016/j.apradiso.2011.05.020

Sutherland RA. 2000. Bed sediment associated trace metals in an urban stream, Oahu. Hawaii Environmental Geology, 39: 611-627. DOI: 10.1007/s002540050473
Tao Y, Yuan Z, Xiaona H, Wei M. 2012. Distribution and bioaccumulation of heavy metals in aquatic organisms of different trophic levels and potential health risk assessment from Taihu lake, China. Ecotoxicology and Environmental Safety, 81: 55-64. DOI:10.1016/j.ecoenv.2012.04.014

Tekin-Özan S, Aktan N. 2012. Relationship of Heavy Metals in Water, Sediment and Tissues with Total Length, Weight and Seasons of Cyprinus carpio L., 1758 From Işikli Lake Turkey). Pakistan J. Zool., 44(5): 1405-1416.

Vrhovnik P, Smuc NR, Dolenec T, Serafimovski T, Dolenec M. 2013. An evaluation of tracemetal distribution and environmental risk in sediments from the Lake Kalimanci (FYR Macedonia). Environmental Earth Science, 70: 761775. DOI: $10.1007 / \mathrm{s} 12665-012-2166-1$.

Yang J, Chen L, Liu L, Shi We, Meng X. 2014. Comprehensive risk assessment of heavy metals in lake sediment from public parks in Shanghai. Ecotoxicology and Environmental Safety, 102: 129-135. DOI: 10.1016/j.ecoenv.2014.01.010.

Yi Y, Yang Z, Zhang S. 2011. Ecological risk assessment of heavy metals in sediment and human health risk assessment of heavy metals in fishes in the middle and lower reaches of the Yangtze River basin. Environmental Pollution, 159: 2575-2585. DOI: 10.1016/j.envpol.2011.06.011

Yilgor S, Kucuksezgin F, Ozel E. 2012. Assessment of Metal Concentrations in Sediments from Lake Bafa (Western Anatolia): An Index Analysis Approach. Bull Environ Contam Toxicol., 89:512-518 DOI 10.1007/s00128-0120699-3.

Zahra A, Hashmi MZ, Malik RN, Ahmed Z. 2014. Enrichment and geo-accumulation of heavy metals and risk assessment of sediments of the Kurang Nallah-Feeding tributary of the Rawal Lake Reservoir, Pakistan. Science of the Total Environment 470-471: 925-933. DOI: 10.1016/j.scitotenv. 2013.10.017 